Paidéia, 2001, 11(20), 85-88

\title{
OS ESPECIALISTAS DA INFÂNCIA E DA JUVENTUDE: PRODUZINDO VERDADES COMPETENTES ${ }^{1}$
}

\author{
Cecília Maria Bouças Coimbra \\ Universidade Federal Fluminense ${ }^{2}$
}

\begin{abstract}
RESUMO: Este texto pretende abordar, a partir das experiências de um estágio curricular no Juizado da Infância e da Juventude, a maneira de serem criadas certas identidades modelares e cristalizadas para os que procuram os serviços de assistência, delineando como, ao longo do século XX, foram produzidas formas de pensar, perceber e sentir as classes subalternas, fazendo uma vinculação estreita entre pobreza e criminalidade, violência e periculosidade, avaliando, ao mesmo tempo, o papel aí exercido pelos profissionais da área psi.
\end{abstract}

Palavras-chaves: Identidade; pobreza; periculosidade; atribuição psi

\section{CHILDHOOD AND YOUTH PROFESSIONALS: HOW TO PRODUCE A COMPETENT TRUTH}

\begin{abstract}
S: This text analyses the experience brought by one curricular stage developed within Childhood and Youth Court, in the sate of Rio de Janeiro, seeing how are created certain identities, attributed to people that are directed to services and assistance. It tries to delineate how, during the XX Century, were produced ways of thinking, perceiving and feeling about the popular classes, doing a tightly tie between poverty and criminality, violence and dangerousness; at the same time, it is analyzed the role played by psi professionals.
\end{abstract}

Key-Words: Identity; Poverty; Dangerousness; Psi attribution

\section{Introdução}

As experiências trazidas por um estágio curricular desenvolvido num Juizado de Infância e Juventude no Estado do Rio de Janeiro ${ }^{3}$ estão na base das reflexões neste artigo que se propõe analisar como vêm sendo produzidas certas identidades modelares e cristalizadas para aqueles que são encaminhados e/ou se dirigem a serviços e estabelecimentos de assistência. Inicialmente, discute-se como, ao longo do nosso século, foram sendo produzidas certas formas de pensar, perceber e sentir as classes subalternizadas quando se liga indissoluvelmente pobreza com criminalidade, violência e periculosidade. Paralelamente, podem-se focalizar as práticas de alguns profissionais psi no cotidiano dos Juizados,

\footnotetext{
${ }^{1}$ Artigo recebido para publicação em 04/2000, aceito em 06/2001

2 Endereço para correspondência: Cecília Maria Bouças Coimbra

${ }^{3}$ Estágio sob a coordenação da autora desde 1993 no Serviço de Psicologia Aplicada da Universidade Federal Fluminense.
}

atravessadas e constituídas por essas competentes produções de subjetividades, e verificar como elas têm sido também complementos importantes no fortalecimento dessas identidades como se elas fizessem parte da natureza dessas crianças e adolescentes pobres e de suas famílias.

\section{Pobreza Sinônimo de Criminalidade ${ }^{5}$}

Foucault (1988) já assinalava que, a partir do capitalismo industrial, quando emergem as sociedades disciplinares ${ }^{6}$, as classes dominantes passam não mais, como antes, a se preocupar com as infrações às normas cometidas pelos sujeitos, mas sim com o

\footnotetext{
${ }^{5}$ Esta parte é uma síntese com algumas modificações, de um capítulo do trabalho de Pós-Doutorado da autora "Discursos sobre Segurança Pública e Produção de Subjetividades: a violência urbana e alguns de seus efeitos", realizado no Núcleo de estudos de Violência da USP, em 1998.
} 
que eles poderiam vir a infligir. Ou seja, o controle não será somente sobre o que se é, o que se faz, mas também sobre o que se poderá vir a ser, vir a fazer; sobre as virtualidades, portanto. Tal dispositivo estará presente em todas as histórias de exclusões e marginalizações que marcam o mundo ocidental a partir do século XIX.

Em nosso país, que traz como herança mais de 300 anos de escravidão, o controle das virtualidades exercerá um papel fundamental na forma de se pensar, perceber e sentir a pobreza.

A própria ciência que emerge no século XIX na Europa, justifica os fundamentos da escravidão através de suas teorias racistas.

Essas teorias - baseadas nos ideais eugênicos - apontam as misturas raciais indesejáveis, aquelas que explicam as enfermidades, imbecilidades, indolências, doenças físicas e morais de todos os tipos e que, portanto, estariam nas origens dos perigos sociais, Elas correm juntas e são realimentadas pela obra de Darwin (1859), pelo darwinismo social ${ }^{7}$ e pela obra de Morel (1857).

Coroando e seguindo as pegadas de todas essas teorias encontramos no Brasil, do final do século $\mathrm{XIX}$ e por todo o século XX, o movimento higienista que, extrapolando o meio médico, penetra nos mais diferentes setores sociais aliando-se a pedagogos, arquitetos/urbanistas e juristas, dentre outros. Tal movimento vai redefinindo os papéis que devem desempenhar em uma sociedade capitalista a família, a criança, a mulher, os espaços urbanos, as classes subalternizadas.

No discurso médico da época, a rua, os locais públicos vão sendo produzidos como a "grande escola do mal" onde estariam os "menores", a "infân-

\footnotetext{
'Segundo Foucault (1974) sociedades que emergiram com o capitalismo industrial. nos séculos XVI e XIX, e que se caracterizam por disciplinarizar, controlar, normatizar fixando os sujeitos em determinados territórios que funcionam como sistemas fechados como familia, escola, fábrica, hospital, prisão, etc. Segundo Foucault estas sociedades disciplinares incluem os sujeitos para excluí-los socialmente.

${ }^{7}$ Interpretações as mais variadas da "teoria de Darwin aplicadas à análise das sociedades humanas e dos indivíduos (na psicologia, lingüística, antropologia, pedagogia e sociologia) servindo muitas vezes de base para justificar diversas formas de dominação, ou até mesmo a doutrina liberal da economia como na Inglaterra pelo argumento da livre concorrência ou do livre mercado através da seleção do mais forte e adaptado". In Lobo. L.F. Os Infames da História: a instituição das deficiências no Brasil. - Tese de Doutorado - PUC/RJ, 1997- $1^{\text {' }}$ vol. $\mathrm{p}, 138,139$
}

cia em perigo" - aqueles pobres que convivendo com os que já delinqüiram - inevitavelmente constituiriam a "infância perigosa".

Importante lembrar que o século XIX, na Europa, caracteriza-se por fortes movimentos de massa nas ruas e, justamente, as práticas/discursos das elites dominantes constróem as imagens das multidões e das ruas como sinônimos de perigo. Sennett (1988) aponta que naquele período começou-se a produzir o esvaziamento dos espaços públicos e a ênfase ao território do privado. Os espaços públicos, por todo o século XX, passam a ser desqualificados, percebidos como ameaçadores e que, portanto, precisariam ser evitados. Daí, as reordenações urbanas, ocorridas em nosso país que, desde o início deste século, nos moldes do higienismo, implantam uma terapêutica para tratar das cidades. Estas, destinadas à velocidade, tornam-se espaços de circulação e não mais lugares de encontros. Os miseráveis expulsos dos centros das cidades e de suas zonas nobres vão para os subúrbios e periferias: para os "territórios dos pobres", no dizer de Santos (1994).

Da mesma forma que as teorias racistas, eugênicas e higienistas, as reordenações urbanas têm se caracterizado pela segregação, exclusão e isolamento da pobreza corroborando a crença de que com ela estão as doenças, os perigos, as ameaças, a violência. Daí, o ataque que é feito diretamente sobre o espaço onde a sociabilidade dos pobres viceja e se fortalece: a rua. Esta passa a ser vista como ameaça à ordem, local da barbárie, do promíscuo, das doenças, do tumulto, do perigo, da criminalidade. Seus habitantes identificados com o atraso, a sujeira, a doença, a feiura e a barbárie precisam ser afastados e evitados, pois são fonte de todos os malefícios, vícios e degenerações.

Ao lado da "morte das ruas" (Josephson, 1994), da sua desqualificação, surge a exaltação da casa, do lar burguês, da vida privada, lugar de refúgio contra as ameaças externas: o "ninho protetor".

Já o filósofo Kant, no século XVIII, a isto se referia ao afirmar que:

"A casa, o domicílio, é a única barreira contra o horror do caos, da noite e da origem obscura (...); opõe-se à evasão, à perda, à ausência. Pois organiza sua ordem 
interna, sua civilidade, sua paixão (...). A identidade do homem é portanto domiciliar; eis por que o revolucionário, aquele que não possui eira nem beira e, portanto, nem fé, nem lei, condena em si toda a angústia da vagabundagem (...). O homem de lugar nenhum é um criminoso em potencial" (Perrot, 1991).

\section{Os Especialistas e a Produção de Verdades Com- petente}

A crença de que existe uma determinada natureza no homem - domiciliar, intimista, familiarista, dentre outras identidades - que o distingue dos nãohumanos, vem sendo afirmada, portanto, ao longo dos dois últimos séculos. Ao fugir a essa natureza, a pobreza tem forjado uma outra identidade para si: perigosa, violenta e inexoravelmente criminosa.

As práticas consideradas científicas e, por isso mesmo, percebidas como objetivas e neutras, produzidas pelos chamados especialistas têm fortalecido tais crenças, como rapidamente acompanhamos nas teorias racistas, eugênicas e higienistas. Tem sido através de enunciados considerados "verdadeiros", porque baseados nos cânones científicos que se desqualificam certos saberes, certas formas de ser e de existir, considerados não-competentes, não-qualificados, porque diferentes do instituído. Em especial, esses saberes têm sido caracterizados como abaixo do nível requerido pela cientificidade e são percebidos, portanto como inferiores.

Segundo Chauí (1982) as ciências têm sido

\section{“(...) poderosos instrumentos de intimidaçāo sócio-política através da noção de competên- cia (...). $O$ discurso e a prática científicos, enquanto competentes, possuem regras pre- cisas de exclusão e inclusão sociais (...)"}

Enquanto profissionais "psi" - também produzidos como peritos, especialistas que detêm o saber científico/verdadeiro/objetivo/neutro/ universal - porque atravessados/ constituídos por todas essas crenças que ligam pobreza com criminalidade, fortalecemos essas naturezas sobre as classes subalternizadas. Cotidianamente, nossas práticas aceitam e endossam certas identidades que constituiriam os pobres: carências e desestruturações de todos os tipos. Os conceitos de "carência emocional" e "família desestruturada", por exemplo, estão presentes em muitas falas de especialistas e laudos psicológicos dados a criança e adolescentes que passam por esses estabelecimentos - e muitos outros que "assistem" a crianças e adolescentes pobres e a suas famílias - e, em realidade, têm fortalecido o que os diferentes dispositivos sociais vêm afirmando sobre a pobreza: os subalternizados acreditam na sua incapacidade, no seu não-saber, e aceitam a inferioridade que a sociedade lhes impõe. Embasados nessas crenças são convencidos de que aqueles que não possuem informações "competentes" não podem se expressar e que podem e devem ser excluídos. Legitimam-se, assim, estigmatizações, marginalizações, exclusões.

\section{Conclusões}

Finalizando, são pontuadas algumas questões relativas às práticas desses profissionais, enfatizandose a superação dessas identidades percebidas como fixas e imutáveis, desse modelos, dos binarismos e dicotomias tão presentes nessas práticas e naturalizados em nosso mundo.

Para finalizar este texto e não este assunto, pois acredito que ainda temos muito a caminhar, trago algumas questões, muitas dúvidas, problemas e desafios que se colocam para todos nós.

Como nós, especialistas "psi" podemos contribuir na luta para um efetivo exercício da cidadania, se marcamos com nossas práticas o nosso lugar como o do saber verdadeiro/científico/objetivo/neutro/universal? Se, em muitos casos, não colocamos em análise esse lugar e esse nosso monopólio do saber? Se, ao contrário, reforçamos o "discurso da competência" e o naturalizamos, pois aceitamos a necessidade desses mesmos especialismos?

Como romper com a produção desse não-saber, da desqualificação, incompetência e periculosidade atribuídos à pobreza?

Como denunciar o caráter anti-natural desses especialismos que trazem para o corpo social, dentre outros efeitos, o não-saber sobre o que se produz, para que se produz e que funções tem essa produção 
em nossa sociedade?

Penso que para que possamos nos implicar um pouco mais efetivamente com algumas transformações temos que começar a colocar em análise esse lugar de saber-poder que ocupamos. Para tal, é com nossas próprias práticas que poderemos desnaturalizar as "verdades" que nos aprisionam, as dicotomias e binarismos que ajudamos a construir em nosso cotidiano.

\section{Referências Bibliográficas}

Chauí, M. (1982). O Que é Ser Educador Hoje? Da Arte à Ciência: a morte do educador. Em: C.R. Brandão (Org.), Educador: Vida e Morte. (pp. 58-59). Rio de Janeiro: Graal.

Darwin, C. (1859). A Origem das Espécies.........

Foucalt, M. (1996). A Verdade e as Formas Juridicas. Rio de Janeiro: Nau.

Josephson, S. (1994). A Morte das Ruas: estudo das relações público e privado nos condomínios exclusivos. Rio de Janeiro. Dissertação de Mestrado, Universidade Estadual do Rio de Janeiro, Rio de Janeiro.

Morel (1857). Tratado das Degenerescências ........

Perrot, M (1991). Maneiras de Morar. Em M. Perrot

(Org.). História da Vida Privada 4 (p. 308). São Paulo: Companhia das Letras.

Tais experiências têm sido cotidianamente pensadas/ enriquecidas não só no espaço das supervisões do estágio, mas com outra equipe que compõe um trabalho de pesquisa e extensão - PIVETES (Programa de Intervenção Voltado às Engrenagens e Territórios de Exclusão Social) ${ }^{4}$.

${ }^{4}$ Programa de Pesquisa e Extensão funcionado junto ao Departamento de Psicologia da Universidade Federal Fluminense desde 1994. 